\title{
BMJ Open Too much information? A document analysis of sport safety resources from key organisations
}

\author{
Sheree Bekker, Caroline F Finch
}

To cite: Bekker S, Finch CF. Too much information? A document analysis of sport safety resources from key organisations. BMJ Open 2016;6:e010877.

doi:10.1136/bmjopen-2015010877

- Prepublication history and additional material is available. To view please visit the journal (http://dx.doi.org/ 10.1136/bmjopen-2015010877)

Received 16 December 2015 Revised 25 March 2016 Accepted 8 April 2016
CrossMark

Australian Collaboration for Research into Injury in Sport and its Prevention (ACRISP), Federation University

Australia, Ballarat, Victoria, Australia

Correspondence to Caroline F Finch; c.finch@ federation.edu.au

\section{ABSTRACT}

Objectives: The field of sport injury prevention has seen a marked increase in published research in recent years, with concomitant proliferation of lay sport safety resources, such as policies, fact sheets and posters. The aim of this study was to catalogue and categorise the number, type and topic focus of sport safety resources from a representative set of key organisations. Design: Cataloguing and qualitative document analysis of resources available from the websites of six stakeholder organisations in Australia.

Setting: This study was part of a larger investigation, the National Guidance for Australian Football Partnerships and Safety (NoGAPS) project.

Participants: The NoGAPS study provided the context for a purposive sampling of six organisations involved in the promotion of safety in Australian football. These partners are recognised as being highly representative of organisations at national and state level that reflect similarly in their goals around sport safety promotion in Australia.

Results: The catalogue comprised 284 resources. More of the practical and less prescriptive types of resources, such as fact sheets, than formal policies were found. Resources for the prevention of physical injuries were the predominant sport safety issue addressed, with risk management, environmental issues and social behaviours comprising other categories. Duplication of resources for specific safety issues, within and across organisations, was found.

Conclusions: People working within sport settings have access to a proliferation of resources, which creates a potential rivalry for sourcing of injury prevention information. Important issues that are likely to influence the uptake of safety advice by the general sporting public include the sheer number of resources available, and the overlap and duplication of resources addressing the same issues. The existence of a large number of resources from reputable organisations does not mean that they are necessarily evidence based, fully up to date or even effective in supporting sport safety behaviour change.

\section{INTRODUCTION}

We have become a society hallmarked by the aphorism 'too much information', or simply 'TMI', as the World Wide Web has ushered in

\section{Strengths and limitations of this study}

- Document analysis is a systematic, qualitative research method for thematically reviewing documents.

- The websites from six organisations were included. These organisations have previously been recognised as key stakeholders in sport safety in Australia, and hence are considered broadly representative of similar organisations.

- This research did not analyse the quality of the content of the resources, and while the importance thereof is recognised, it was outside the scope of this particular study.

an era in which information is at our fingertips. It has been suggested that, for up to $61 \%$ of American adults ${ }^{1}$ and $78 \%$ of Australian adults, ${ }^{2}$ their first port of call for healthcare information is searching the internet, or what is colloquially referred to as 'Dr Google'. Moreover, it has been shown that if a doctor working in primary care were to relay all of the recommended primary healthcare information to patients at every opportunity that presented itself, it would take an average of $7.4 \mathrm{~h}$ of their time each day. ${ }^{3}$

The field of sport injury prevention has seen a marked increase in information available through scientific and medical journals in recent years, as evidenced by a systematic review of over 12000 published research articles. ${ }^{4}$ Coinciding with this, there has been a concomitant proliferation of lay safety information, such as policies, fact sheets and posters, on injury prevention strategies intended for informing the general sporting public, ostensibly based on the aforementioned scientific evidence. This has been accompanied by a strong trend towards electronic dissemination of such information, ${ }^{5}$ possibly because of the relative ease of access and cost-effectiveness of developing and disseminating resources in soft-copy rather than hard-copy form. 
In light of this, this paper presents a first step in collating, and categorising, sport safety resources that key organisations distribute electronically via their websites. The aim of this research was to determine the number, and thematically categorise the type and topic focus, of resources disseminated by a set of key organisations which curate sport safety promotion information intended for the general sporting public.

\section{METHODS}

\section{Describing the research context}

This study was part of a larger investigation, the National Guidance for Australian Football Partnerships and Safety (NoGAPS) project. ${ }^{6}$ A key aim of the broader NoGAPS study was to identify factors that influence the translation of safety promotion interventions into practice in community sport. The partnership aimed to reduce knowledge gaps between (1) policy and practice, (2) efficacy to effectiveness, (3) research knowledge to translation and (4) elite sport and community sport. The NoGAPS study provided the context for a clear and well-defined purposive sampling of six organisations for this research study: the Australian Football League (AFL), Victorian Health Promotion Foundation (VicHealth), New South Wales Sporting Injuries Committee (NSWSIC), JLT Sport as a division of Jardine Lloyd Thompson Australia Pty Ltd (JLT Sport), Sport and Recreation Victoria (SRV) and Sports Medicine Australia (SMA). These organisations were originally chosen for the NoGAPS project because they are recognised as key stakeholders in safety promotion in Australia, especially as it applies to the sport of Australian football. ${ }^{6}$ This group is therefore representative of organisations at national and state level that reflect similarly in their goals around safety promotion in sport in Australia. Details of our engagement with these organisations, though regular consultation and meetings throughout the NoGAPS project, have been published elsewhere.

\section{Ethical approval}

Ethical approval was granted by the Federation University Australia Human Research Ethics Committee (Ballarat, Australia).

\section{Identifying sources of safety information}

Currently, in Australia, there is no single source of information or set of comprehensive resources available for sport safety promotion, or to inform the general sporting public about the risks associated with sport participation. Sport settings, therefore, need to actively seek and use a range of safety promotion information from a variety of sources, often found online. The websites of the NoGAPS organisations provide key example sources of this type of information. This study collected, catalogued and thematically categorised the types and topic focus of all safety promotion resources applicable to sport settings available from the websites of the NoGAPS organisations between April and October 2013, inclusive.

\section{Identifying types of resources}

First, the types of resources available from the NoGAPS organisations that could be included in a catalogue of safety promotion resources for community sport clubsrather than elite sport settings-in Australia were determined. Starting with formal document types, the World Health Organization definition for policy ( 8 p4) was the starting point to identify relevant formal resource types: 'A policy on...injury prevention is a document that sets out the main principles and defines goals, objectives, prioritized actions and coordination mechanisms, for preventing intentional and unintentional injuries and reducing their health consequences'. The words 'action plan', 'strategy' and 'programme' and their synonyms were added as also denoting types of resources. ${ }^{8-10}$ Second, the practical end versions of resources (such as posters/fact sheets/guidelines) and all synonymous derivatives were included. The option to add to this list of types of resources as they emerged was maintained throughout the data collection process.

\section{Search strategy}

To ensure that no resources were missed, two approaches were used in collating resources for the catalogue: (1) an online search of each NoGAPS organisation website by the first author; and (2) a direct email request to each NoGAPS organisation representative.

\section{Website search}

The website search was conducted first. The home page of each NoGAPS organisation website was accessed in April 2013. This page was scanned for links to safety promotion resources relevant to sport settings, before a systematic search of the full website was conducted. Owing to the continually evolving nature of websites as information is updated, this search was repeated 6 months later. Repeating the search ensured that the final catalogue represented an accurate reflection of the resources available from these organisations over the course of 6 months in 2013-so as to ensure inclusion of new resources that were added to the websites over that time period. Full details of the systematic search are detailed in online supplementary material 1.

\section{Direct request}

A direct request for the website resources was also made to each NoGAPS organisation's nominated representative, by email, in May 2013, requesting the same types of resources as sourced in the online search. This was to ensure that no resources were missed. Full details of this approach are detailed in online supplementary material 1 .

\section{Collation of catalogue}

Two catalogues (one for each search strategy) of collected resources were created using NVivo qualitative data analysis software (QSR International Pty Ltd. V.10, 2012). Each search strategy catalogue contained a list of 
the resources identified and retrieved, organised by the NoGAPS organisation providing it.

The two catalogues were then merged, duplicate resources between catalogues removed and a final catalogue of safety promotion resources available from the NoGAPS organisations was collated. This process is shown in figure 1 .

\section{Document analysis}

The topics of items included in the final catalogue were categorised for themes using document analysis, a systematic, qualitative research method for thematically reviewing documents. ${ }^{11}$ The catalogue was coded first by resource type starting with policy and its identified derivatives, second by the less formal document types and finally by including new types of resources as codes as they emerged. The second theme coded for was the sport safety issue/s addressed by the resource, based on resource title alone, and adding codes to the sport safety issue theme as they emerged. Each of these two themes (type and issue) was then depicted using NVivo-generated data visualisation Word Clouds that encode word frequency information via font size and font colour/shade, ${ }^{12}$ as shown in figures 2 and 3 .

\section{RESULTS}

A total of 284 safety promotion resources were included in the final catalogue, demonstrating a large number of individual resources available for sport settings in Australia from these NoGAPS organisations alone. The types of resources in the catalogue are shown in table 1 and figure 2. As can be seen in table 1, the NoGAPS organisations disseminated more practical forms of

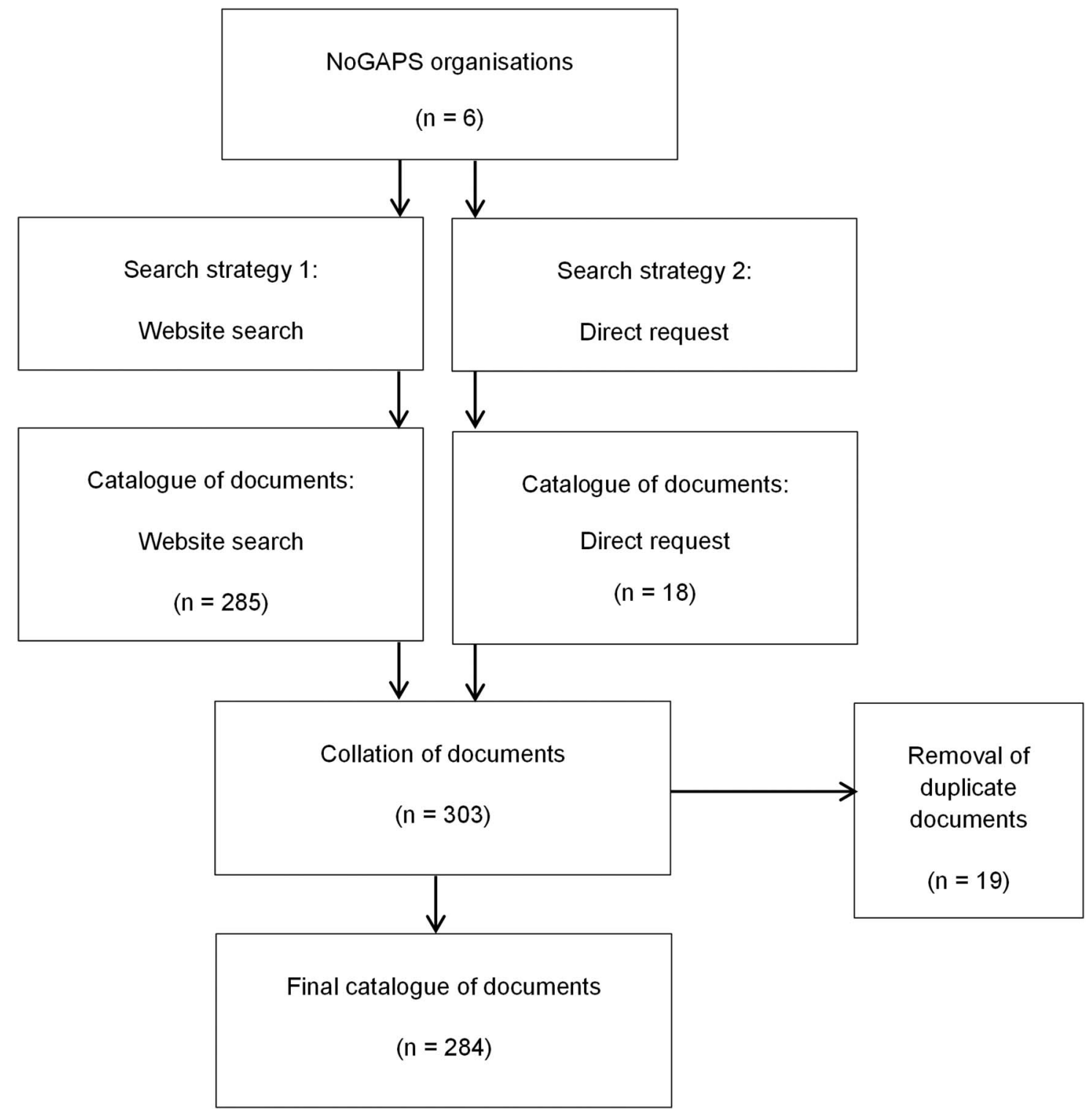

Figure 1 Search strategy used to identify the sport safety resources available from the NoGAPS organisations. NoGAPS: National Guidance for Australian Football Partnerships and Safety project. 


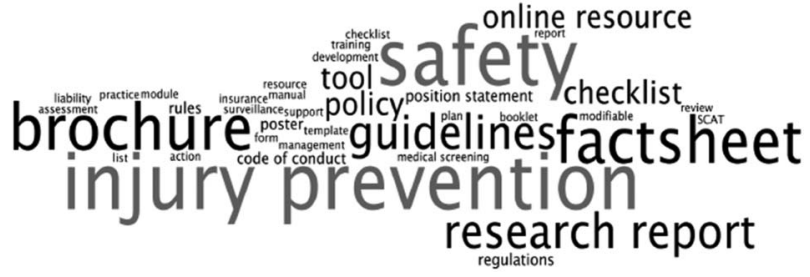

Figure 2 Word Cloud of most common types of sport safety resources available from the NoGAPS organisations. NoGAPS: National Guidance for Australian Football Partnerships and Safety project.

resources, such as fact sheets and flyers, than they did formal policies or regulations. Resources aimed at knowledge translation through education and guidance, such as research reports and guidelines, were the second and third most common types of documents disseminated by these organisations. Figure 2 clearly depicts the numerous types of resources (such as fact sheets), with the frequency of their appearance in the catalogue indicated by font size.

The range of sport safety issues addressed by items within the catalogue is shown in table 2 and figure 3 . Table 2 shows that resources for the prevention of physical injuries were the most frequent, which may be due to the focus of the sports injury prevention field being predominantly on biomechanical and musculoskeletal interventions. Resources for sport-specific injury prevention guidelines were the second most frequent issue addressed by the documents in this catalogue. This covered very popular sports such as running and cricket, but also included resources for less popular sports such as aerobics and in-line skating (rollerblading). Third, risk management and safety procedures, such as match day checklists, were well covered by all six organisations. In addition to injury prevention resources, four organisations also disseminated broader health promotion resources such as physical activity promotion for diabetes prevention. Figure 3 depicts the most common topic issues (such as concussion)-with frequency indicated by font size-as well as the target groups (such as women or children) and the sports they addressed (such as Australian football).

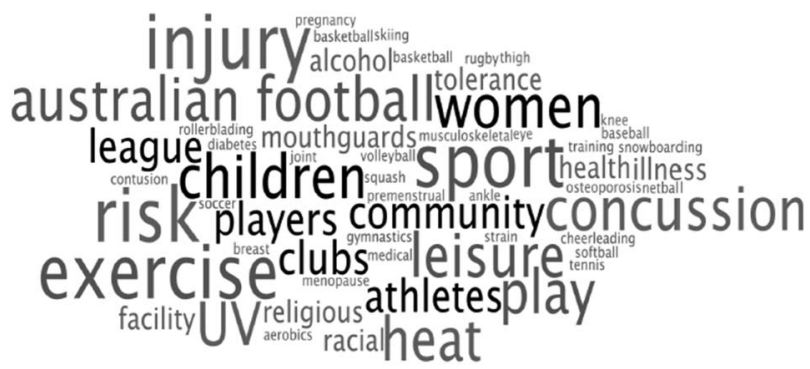

Figure 3 Word Cloud of most common sport safety issues, target groups and sports found in the sport safety resources available from the NoGAPS organisations. NoGAPS: National Guidance for Australian Football Partnerships and Safety project.
Table 3 depicts the considerable duplication of resources for single sport safety issues across and within organisations. For example, there were 15 identified resources for concussion, including three duplicate documents, from two organisations. Similarly, there were 11 resources for heat/ultraviolet light protection from four different organisations, with three duplicate documents.

\section{DISCUSSION}

This study is the first worldwide to analyse the number, type and topic focus of safety promotion resources available online for sport settings, across a set of key organisations. The resultant catalogue of resources addressing an overlapping array of issues is reflective of the rapid development and rise in the popularity of sport, and its associated safety problems, which has occurred without the concomitant development of comprehensive or targeted safety initiatives. ${ }^{13}$ Moreover, it creates and perpetuates the very same 'too much information and too little time' issue in information dissemination and availability as described in the introduction to this paper.

Ideally, international, national and community sport organisations should collaborate to address elite-level and community-level safety by setting rules and norms of conduct. ${ }^{14}$ Instead, the paucity of a national comprehensive sport safety policy in Australia has led to an environment focused on fragmented safety issues that often only cover single or limited concerns, which is often not mandated in a top-down manner. ${ }^{15}$ The problem is exacerbated because community sport has a heavy reliance on volunteers adopting multiple roles, with very little health-related knowledge or experience. ${ }^{16-18}$ This results in a smaller pool of sustained knowledge and expertise, particularly around the issue of safety practices, ${ }^{15-17}$ compounded by smaller budgets and personnel time constraints. ${ }^{18}$ Formal safety policies and practices, in the form of written or unwritten guidelines, are therefore often lacking or inconsistently implemented in these settings. ${ }^{16} 1920$ This lack of a comprehensive and coordinated approach to sport safety could result from sport clubs themselves being unaware of available information, or because of poor dissemination of formal policy and related information by overarching sporting organisations. ${ }^{17}$ While most sporting organisations now recognise the importance of safety issues, few sport clubs currently have the resources, staffing, motivation or direct mandate to administer measures to counteract risk. ${ }^{13}$

Organisations such as those represented by the NoGAPS partners aim to bridge this gap by providing and disseminating safety promotion information in the form of a range of resources for a variety of sport settings, as evidenced by the catalogue in this study. The extent of this catalogue and the duplication within it, in turn, may be indicative of the current ad hoc process used in the development of sport safety resources. The development of new resources appears to be largely reactive to specific requests from sport clubs in reaction 
Table 1 The type and number of sport safety promotion resources available from the six NoGAPS organisations

\begin{tabular}{lll}
\hline Resource type & $\begin{array}{l}\text { Number of separate } \\
\text { resources identified }\end{array}$ & $\begin{array}{l}\text { Number of NoGAPS organisations } \\
\text { providing resources of this type }\end{array}$ \\
\hline Fact sheet/information sheet/booklet/pamphlet/brochure/ & 116 & 6 \\
letter/summary/flyer & 46 & 6 \\
Education/research/reports & 36 & 5 \\
Manual/guidelines/framework/guide & 30 & 6 \\
Checklist/form/template/tool/system/action plan/sample & 23 & 5 \\
Policy & 7 & 3 \\
Acts/rules/regulations & 7 & 3 \\
Position statement & 6 & 2 \\
Poster & 5 & 2 \\
Code/code of conduct/code of behaviour & 5 & 2 \\
Links to other online resources & 3 & 3 \\
\hline Resource list/order form & &
\end{tabular}

NoGAPS: National Guidance for Australian Football Partnerships and Safety project.

to specific incidents or media coverage, or resulting from outputs of research projects, rather than through targeted broad proactive prevention efforts. This development process perpetuates replication of the types of resources available across organisations, and duplication of resources covering the same safety issues within and across organisations. Duplication of resources addressing the same issue suggests a piecemeal approach and lack of strategic accumulation of existing safety knowledge and initiatives. Further, consideration for the needs of the sport setting itself remains underexplored, and it is imperative that the end-user perspective is taken into account if safety promotion is to be effective, ${ }^{21}$ as it is unknown as to whether or not these resources have been evaluated for effectiveness across different contexts. It is apparent from this study that people seeking sport safety information have to contend with the availability of a variety of overlapping resources, from different organisations, addressing the same sport injury prevention issue in either the same or different ways. An unintentional rivalry of resources for safety promotion activities is thus created, potentially rendering information dissemination efforts ineffective.
Not surprisingly, considering the comparatively vast base of scientific literature, the prevention of physical injury in sport (eg, concussion or anterior cruciate ligament injuries) was most commonly addressed in resources from the NoGAPS organisations. The websites of the NoGAPS organisations also typically provided more of the practical and less prescriptive end versions of policies, such as fact sheets, than formal policies themselves.

It was beyond the scope of this study to assess the quality of the content of resources or to explore how and why they were developed by the organisations. This should be the focus of future research because such factors are likely to influence the uptake and use of such resources by the public. Moreover, mere existence of online resources does not necessarily equate to evidencebased, useful or transferable information. A recent study of online concussion information found the quality to be varied with many key facts omitted from resources, even though the research knowledge base for safety practices to address concussion is sound. ${ }^{22} \mathrm{~A}$ more recent qualitative review of sports concussion educational information $^{23}$ noted that simply making information available

Table 2 The sport safety issues addressed in the catalogue of safety resources available from the six NoGAPS organisations

\begin{tabular}{|c|c|c|}
\hline Sport safety issue & $\begin{array}{l}\text { Number of separate } \\
\text { resources identified }\end{array}$ & $\begin{array}{l}\text { Number of NoGAPS organisations } \\
\text { providing resources addressing issue }\end{array}$ \\
\hline Physical injury prevention (including concussion) & 61 & 5 \\
\hline Sport specific & 58 & 2 \\
\hline Risk management/safety procedures/first aid & 48 & 6 \\
\hline $\begin{array}{l}\text { Environmental issues (heat/ultraviolet/lightning/ground } \\
\text { conditions/facilities/infectious diseases/blood) }\end{array}$ & 33 & 6 \\
\hline $\begin{array}{l}\text { Social behaviours (doping/alcohol/gambling/smoking/ } \\
\text { racial tolerance/religious tolerance/GLTBQIA* } \\
\text { tolerance) }\end{array}$ & 20 & 5 \\
\hline Health promotion & 16 & 4 \\
\hline
\end{tabular}


Table 3 The duplication of resources for specific sport safety issues, across and within the six NoGAPS organisations

\begin{tabular}{llll}
\hline Sport safety issue & $\begin{array}{l}\text { Total number of resources } \\
\text { identified across all NoGAPS } \\
\text { organisations }\end{array}$ & $\begin{array}{l}\text { Number of NoGAPS } \\
\text { organisations providing } \\
\text { resources on this broad topic }\end{array}$ & $\begin{array}{l}\text { Number of duplicate } \\
\text { resources across NoGAPS } \\
\text { organisations }\end{array}$ \\
\hline Risk management/ & 26 & 5 & 2 \\
safety procedures & & 2 & 3 \\
Concussion & 15 & 4 & 3 \\
Heat/ultraviolet & 11 & 3 & 0 \\
Respect/tolerance & 9 & 3 & 0 \\
First aid & 9 & 2 & 0 \\
Facilities & 8 & 2 & 0 \\
Doping & 4 & 2 & 0 \\
Ground conditions & 4 & 3 & 0 \\
Alcohol & 3 & 2 & 0 \\
Smoking & 2 & 2 &
\end{tabular}

NoGAPS: National Guidance for Australian Football Partnerships and Safety project.

increases knowledge, but does not produce long-term behaviour change. Similarly, editorials and opinion pieces ${ }^{24-26}$ have stated that, despite the existence of scientific evidence, the effectiveness of sport injury prevention interventions remains decidedly ineffective because little attention has been given to information dissemination needs and processes.

It must be stressed here that it is not interventions per se that work, but rather it is people that make interventions work. $^{27}$ Interventions are always implemented within a wider socioecological context, ${ }^{28}$ and attitudes, individuals, institutions and societal constraints all play a role. ${ }^{29}$ Furthermore, resources are never embedded into contexts as a singular entity, rather they form part of a range of rival interventions/policies/resources, ${ }^{29}$ as this study has shown. The perpetual development and dissemination of evermore resources, without recognising the potential interplay thereof, or subsequent evaluation as to effectiveness within context, only adds to this rivalry.

\section{Study limitations}

This study did not analyse the quality of the content of the resources, and, as discussed, while the importance thereof is recognised, it was outside the scope. The websites from only six organisations were included; however, these organisations have previously been recognised as key stakeholders in sport safety in Australia and hence are considered broadly representative of similar organisations. ${ }^{6}$ While this study was conducted using a set of Australian organisations, we believe the issues raised are indicative of the nature of the development of sport and its concomitant safety issues in similar countries globally. This study did not collect information on how the need for the particular resources was first identified or how the specific resources were developed by the organisations. It will be an important next research step to evaluate organisational process and intentions behind resource development and dissemination strategies. The first author completed the document analysis and thematic coding, with review input from the coauthor. Notwithstanding these limitations, and as described elsewhere, ${ }^{7}$ there was significant consultation with, and recognition of this research by, the NoGAPS organisations, each of which was invited to comment on the compiled catalogue and findings relevant to their organisation.

\section{CONCLUSION}

This study used a qualitative document analysis approach to identify and describe how many and what types of resources are available for sport settings from the websites of key organisations, as well as the sport safety issues they address. The findings highlight important issues that are likely to influence the uptake of safety advice and information by the general sporting public. First, the general sporting public has access to at least 284 resources for safety promotion from these six organisations alone. Second, the proliferation of resources on apparently the same safety issues only adds to the rivalry of limited time and ability of end users to identify and implement safety initiatives within their sport settings. This is exacerbated by the fact that those accessing the resources and needing to make safety decisions are likely to be volunteers without formal sport injury prevention training or health backgrounds. If sport bodies do not mandate safety actions through higher levels of administration, there is potential for confusion at community sport club level as to what action to take when there are many possible options available to them though different resources. Third, the mere existence of a large amount of resources from reputable organisations does not mean that they are necessarily evidence based, fully up to date or even effective in supporting sport safety behaviour change.

Over recent years, there has been a shift to online dissemination of sport safety promotion information, ${ }^{22}$ but much of this has not drawn on well-established principles of social marketing to direct it. ${ }^{30}$ Unfortunately, this ad hoc approach has led to a proliferation of resources that are neither regulated nor scrutinised for 
quality. Sport settings, therefore, have access to a proliferation of rival resources, which reflects a potentially inefficient and ineffective manner in which to promote safety. Research can only have an impact on sport safety practice if evidence is consolidated and presented in such a way that effective practices are triggered, rather than creating a rivalry for implementation efforts without concomitant evaluation for effectiveness. Rather than merely calling for more research, or for more knowledge translation, we conclude that there is an immediate need to undertake research to better understand how to focus information accumulation, resource consolidation and better evaluation of the effectiveness of sport safety resources. Most importantly, future development and dissemination of sport safety resources will require full consideration of the needs of the end user from the outset.

Twitter Follow Sheree Bekker at @shereebekker and Caroline F Finch at @CarolineFinch

Acknowledgements The authors would like to thank the NoGAPS partnership organisation representatives for their assistance in the data collection phase, and their feedback on the findings of this research. The authors would also like to thank Dr PE White for earlier input to this research.

Contributors SB led this work as part of her PhD studies-designed the study, led its conduct, had the major role in paper writing and is responsible for the overall content as guarantor. CFF contributed to the design of the study and the writing of the paper.

Funding SB was supported by a Federation University Australia International Postgraduate Scholarship. This study is part of her PhD work, under the cosupervision of the coauthor. CFF was supported by a National Health and Medical Research Council (NHMRC) Principal Research Fellowship (ID 1058737). This study was partially funded by an NHMRC Partnership Project Grant (ID 565907) with additional support (cash and in kind) from the project partner agencies: the Australian Football League (AFL); Victorian Health Promotion Foundation (VicHealth); NSW Sporting Injuries Committee (NSWSIC); JLT Sport, a division of Jardine Lloyd Thompson Australia Pty Ltd, Sport and Recreation Victoria (SRV); and Sports Medicine Australia (SMA). The Australian Centre for Research into Injury in Sport and its Prevention (ACRISP) is one of the international research centres for the prevention of injury and protection of athlete health supported by the International Olympic Committee.

Competing interests None declared.

Ethics approval Federation University Australia Human Research Ethics Committee.

Provenance and peer review Not commissioned; externally peer reviewed.

Data sharing statement No additional data are available.

Open Access This is an Open Access article distributed in accordance with the Creative Commons Attribution Non Commercial (CC BY-NC 4.0) license, which permits others to distribute, remix, adapt, build upon this work noncommercially, and license their derivative works on different terms, provided the original work is properly cited and the use is non-commercial. See: http:// creativecommons.org/licenses/by-nc/4.0/

\section{REFERENCES}

1. Fox S, Jones S. The Social Life of Health Information 2011: Pew Internet \& American Life Project. Washington DC; 2011. http://www. pewinternet.org/files/old-media/Files/Reports/2011/PIP_Social_Life_ of_Health_Info.pdf (accessed 4 Dec 2015).

2. Research Australia. Australia speaks! Research Australia opinion poll. Research Australia Limited, 2015. http://www.researchaustralia. org/advocacy-publications/public-opinion-polls (accessed 4 Dec 2015).

3. Yarnall KS, Pollak KI, Østbye $\mathrm{T}$, et al. Primary care: is there enough time for prevention? Am J Public Health 2003;93:635-41.

4. Klügl M, Shrier I, McBain K, et al. The prevention of sport injury: an analysis of 12,000 published manuscripts. Clin J Sport Med 2010;20:407-12.

5. Verhagen E, Bolling C. Protecting the health of the @hlete: how online technology may aid our common goal to prevent injury and illness in sport. Br J Sports Med 2015;49:1174-8.

6. Finch CF, Gabbe BJ, Lloyd DG, et al. Towards a national sports safety strategy: addressing facilitators and barriers towards safety guideline uptake. Inj Prev 2011;17:e4.

7. Finch CF, Donaldson A, Gabbe BG, et al. The evolution of multi-agency partnerships for safety over the course of research engagement: experiences from the NoGAPS project. Inj Prev 2016 doi:10.1136/injuryprev-2015-041922

8. Schopper D, Lormand J-D, Waxweiler R. Developing Policies to Prevent Injuries and Violence: Guidelines for Policy-Makers and Planners. 2006. http://www.who.int/violence_injury_prevention/ publications/39919_oms_br_2.pdf (accessed 1 Apr 2015).

9. Sethi D, Waxweiler R, Racioppi F. Developing a national policy for injury and violence prevention. Int J Inj Contr Saf Promot 2008;15:53-5.

10. Sminkey L. Finding a common vision for injury prevention. Inj Prev 2006;12:171.

11. Bowen GA. Document analysis as a qualitative research method Qual Res J 2009;9:27-40.

12. Viégas FB, Wattenberg M, Feinberg J. Participatory visualization with Wordle. EEE Trans Vis Comput Graph 2009;15:1137-44.

13. Timpka T, Finch CF, Goulet $\mathrm{C}$, et al. Meeting the global demand of sports safety: the intersection of science and policy in sports safety. Sports Med 2008;38:795-805.

14. Timpka T, Ekstrand J, Svanström L. From sports injury prevention to safety promotion in sports. Sports Med 2006;36:733-45.

15. Poulos R, Donaldson A, Finch C. Towards evidence-informed sports safety policy for New South Wales, Australia: assessing the readiness of the sector. Inj Prev 2010;16:127-31.

16. Casey M, Finch CF, Mahoney M, et al. Sport safety policies and practices in two rural Victorian communities. J Sci Med Sport 2004; 7:226-31.

17. Finch CF, Hennessy M. The safety practices of sporting clubs/ centres in the city of Hume. J Sci Med Sport 2000;3:9-16.

18. Russell K. Child safety and wellbeing in Australian sport. Safeguarding, child protection and abuse in sport: international perspectives in research, policy and practice. Routledge, 2014;116-24.

19. Donaldson A, Hill T, Finch CF, et al. The development of a tool to audit the safety policies and practices of community sports clubs. J Sci Med Sport 2003;6:226-30.

20. Donaldson A, Forero R, Finch CF. The first aid policies and practices of community sports clubs in northern Sydney, Australia. Health Promot J Austr 2004;15:155-61.

21. Donaldson A, Finch CF. Planning for implementation and translation seek first to understand the end-users' perspectives. Br J Sports Med 2012;46:306-7.

22. Ahmed $\mathrm{OH}$, Sullivan SJ, Schneiders AG, et al. Concussion information online: evaluation of information quality, content and readability of concussion-related websites. $\mathrm{Br} J$ Sports Med 2012;46:675-83.

23. Mrazik M, Dennison $\mathrm{CR}$, Brooks BL, et al. A qualitative review of sports concussion education: prime time for evidence-based knowledge translation. Br J Sports Med 2015;49:1548-53.

24. Finch CF. Implementation and dissemination research: the time has come! Br J Sports Med 2011;45:763-4.

25. Kessler RC, Glasgow RE. A proposal to speed translation of healthcare research into practice: dramatic change is needed. Am J Prev Med 2011;40:637-44

26. Hanson D, Allegrante JP, Sleet DA et al. Research alone is not sufficient to prevent sports injury. Br J Sports Med 2014;48:682-4.

27. Pawson R. Evidence-based policy: a realist perspective. Sage, 2006.

28. Hanson D, Hanson J, Vardon P, et al. The injury iceberg: an ecological approach to planning sustainable community safety interventions. Health Promot J Austr 2005;16:5-10.

29. Pawson R, Tilley N. Realistic evaluation. Sage, 1997.

30. Newton JD, Ewing MT, Finch CF. Social marketing: why injury prevention needs to adopt this behaviour change approach. Br J Sports Med 2013;47:665-7.

31. Smith WA. Social marketing: an overview of approach and effects. Inj Prev 2006;12(suppl 1):i38-43. 